\title{
RIVER RUNOFF CHANGES IN THE PAST MILLENNIUM UNDER EXTREME CLIMATIC CONDITIONS IN CHINA
}

\author{
REN, L. ${ }^{1,2^{*}}-$ XIANG, X. Y. ${ }^{3}-$ LIU, W. L. ${ }^{4}$ \\ ${ }^{1}$ State Key Laboratory of Hydrology-Water Resources and Hydraulic Engineering \\ Hohai University, Naijing 210098, China \\ ${ }^{2}$ College of Hydrology and Water Resources, Hohai University \\ Nanjing, 210098, China \\ ${ }^{3}$ School of Geographical Sciences, Southwest University, Chongqing, 400715, China \\ e-mail: ruoqing@swu.edu.cn \\ ${ }^{4}$ Jiangxi Provincial Key Laboratory of Hydrology-Water Resources and Water Environment, \\ Nanchang Institute of Technology, Nanchang, Jiangxi, 330099, China \\ e-mail:weilin_liu@nit.edu.cn \\ *Corresponding author \\ e-mail: renli@hhu.edu.cn; phone: +86-13-5-12-502-509; fax: +86-2-58-378-6621 \\ (Received $10^{\text {th }}$ Apr 2017; accepted $11^{\text {th }}$ Aug 2017)
}

\begin{abstract}
In this study, Poyang Lake catchment with frequent drought and flood disasters in recent years was chosen as the study area. Due to the influence of global climate changes, great changes have taken place in the hydrological and climatic process of Poyang Lake in the past half a century, leading to the increase of extreme weather and hydrological events, shrinkage of water, threat to wetland ecosystem and other problems. First, historical climate data simulated by Atmosphere-Ocean General Circulation Models CCSM4 and ECHAM5 were obtained, which were then applied to Poyang Lake catchment with downscaling method. The hydrological model WATLAC can be driven by upper climate data along with other data so that we get the runoff series in this catchment for the past one thousand years. Based on the research, it was found that the runoff series were in significant positive correlation with precipitation series. The frequency of extreme runoff was consistent with that of precipitation in both models. The peak value was 0.03 , indicating the period was 30 years. The wavelet power spectrum contours of runoff and precipitation series generate significant signals in $20 \sim 40$-year scale. The signal is the strongest in a scale of about 30 years, which further confirms the runoff of Poyang Lake catchment has a macro cycle of about 30 years.
\end{abstract}

Keywords: millennial time scale; climate model; runoff changes; hydrological cycle; Poyang Lake catchment

\section{Introduction}

The Poyang Lake, located in the middle and lower reaches of Yangtze River, is the largest fresh-water lake in China. As one of the few large lakes linking to the river, Poyang Lake plays an important role in water conservation, flood control, climate regulation, ecological protection, etc (Zhu and Zhang, 1997). Due to the influence of global climate change (Guo et al., 2006), great changes have taken place in the hydrological and climatic process of Poyang Lake in the past half a century, leading to the increase of extreme weather and hydrological events (Liu and Ren, 2014), shrinkage of water ( $\mathrm{Yu}$ and $\mathrm{Hu}, 2010)$, threat to wetland ecosystem and other problems (Jiang et al., 2010). Will this situation continue to deteriorate in the future under the influence of climate changes? This paper, based on statistical down-scaling method, thus analyzes 
runoff changes of Poyang Lake in the past millennium under the extreme climatic conditions, aiming to offer scientific guidance for the flood and drought control, ecological protection, development and utilization of water resources and to ensure the coordinated development of the economy and society in this area.

\section{Overview of Research Area}

Poyang Lake is located on the south side of the lower Yangtze River. It is the largest lake connected with Yangtze River. The length from south to north of Poyang Lake is $173 \mathrm{~km}$ and the average width from east to west is $16.9 \mathrm{~km}$, with the width of the widest part at about $74 \mathrm{~km}$. The narrowest part of Poyang Lake is only about $2.8 \mathrm{~km}$ wide. The total length of the lake circle is $1200 \mathrm{~km}$ (Jiang et al., 2007). There are five rivers which contribute to Poyang Lake, namely Ganjiang River, Fuhe River, Xinjiang River, Raohe River and Xiuhe River. After regulation and storage, water in Poyang Lake runs into Yangtze River, which is an important characteristic of seasonal influent-effluent lakes. There are significant periodic variations in water levels of Poyang Lake within the year and among different years. In the wet season, the water level is high and the lake surface is large, with the highest lake surface area being $4070 \mathrm{~km}^{2}$; in dry seasons, the water level is low, with the lowest lake surface area being no more than $150 \mathrm{~km}^{2}$ and the lake water being contained in the channels. The maximum water surface area ever recorded in the wet season is about 27 times of the minimum ever recorded in the dry season, which makes Poyang Lake a lake in wet seasons and several rivers in dry seasons. Variation of water level is mainly induced by the effects of the five rivers mentioned above and the Yangtze River. The main flood season of the 5 rivers is from April to June, when the water level in Yangtze River is comparatively low and the flood water into Poyang Lake can be discharged into the Yangtze River rapidly and the water level in Poyang Lake can be maintained; from July to September, incoming water volume from the five rivers decreases, but water level in Yangtze River is high, which makes the water level in Poyang Lake high; after the end of September, water level in Yangtze River decreases, dry season of the five rivers is coming and the water level in Poyang Lake gradually becomes lower and lower. According to statistical data, the water level variation of Poyang Lake within a year is up to $10 \mathrm{~m}$, which is unique in large lakes $(\mathrm{Xu}$ and Chen, 2009).

\section{Research Methodologies}

\section{Climate Model}

Climate model usually refers to general circulation model (GCM), a mathematicalphysical model of the earth system, which determines the characteristics of the Earth's atmosphere based on mathematical equations formed in dynamic, physical, chemical and biological process of the earth system. The climate model used to simulate changes of the climate system, the response time and process, and the spatial features is a key method to study climate changes on seasonal and interdecadal scale. Climate model involves the simple energy-balance equation and the complex earth system model. Currently the earth system model (ESMs) couples atmosphere, ocean, land and sea ice, with some part of the model even coupling aerosol, carbon cycle, dynamic vegetation and atmospheric chemical process (Liu and Zhang, 2009). Atmosphere-ocean general 
circulation model (AOGCMs) couples the dynamic changes of atmosphere, ocean, land, ice and snow in the climate system. The Coupled Model Intercomparison Project Phase 5 (CMIP5) develops a research plan to simulate climate in the past millennium. More than 20 climate model organizations drive the climate field through the same indicators like solar radiation, volcanic ash, greenhouse gases and etc. And results of near-surface temperature, upper atmosphere and atmospheric circulation characteristics are calculated through physical model like dynamics, heat, and water volume of climate model (Liu, 2011). The USA general climate model: The Community Climate System Model 4 (CCSM4) and European Centre Hamburg Model (ECHAM5) are adopted in this paper to simulate climate (Qin et al., 2014).

The CCSM4 and ECHAM5 are used in the paper as hydrological drive, for they can better simulate the climate in East Asia (Yu and Harrison, 1996). CCSM4 climate model developed by National Center for Atmospheric Research is well received in China (Blackmon et al., 2001). Recently, Tian et al. (2012), Tian and Jiang (2013) have proved that CCSM4 model can better simulate climate features of East Asia and China. Thus it is suitable for long-time climate model researches. The ECHAM5 model proposed by the Max Planck Institute for Meteorology improves the dynamic coupling function of atmosphere, ocean, land and ice and snow, based on ECHAM4 model. The improved model has better simulation (Yu et al., 2009). In recent years, Bueh and Lin (2003) have used ECHAM4 to simulate East Asian monsoon circulation and predict its future changes. Zhai et al. (2009) use ECHAM5 to forecast distribution of drought and flood in China before the year 2050. These researches show that the two models can better simulate regional climate system in China.

So far, most coupled models (AOGCMs) have a relatively low spatial resolution. It is therefore difficult to make reasonable predictions about climate changes on regional scale. The down-scaling methods then come into being, and have since been widely applied to overcome AOGCM's weakness. Statistical down-scaling method is a powerful tool to obtain small-scale climate data from large-scale climate data. Firstly, empirical relationship between large-scale climate factors (predictors) and regional climate factors (predictors) should be established. Then the relationship is used as the output of global climate model or regional climate model and corresponding information of any place can be obtained (Fan et al., 2005).The paper gets related information of Poyang Lake based on the simulation of CCSM4 and ECHAM5 within the framework of IPCC-CMIP5. And monthly temperature and rainfall series of Poyang Lake in the past millennium are obtained through down-scaling methods. Yu et al. (2013) use historical literature and facts from archaeology study to verify the simulation results. The verification shows that GAMs' simulation of rainfall is acceptable. Modern climate data are obtained from monthly temperature and rainfall records of 17 stations of National Secondary Meteorological Station between the year 1951 and 2015, as well as the station positions.

\section{Hydrological Data}

Hydrological model: A Water Flow Model for Lake Catchements (WATLAC) is a mathematical model that simulates surface water and underground water of lake catchment. Unlike most hydrological models with a general summary of underground runoff, WATLAC is improved in this aspect and can better simulate the hydraulic relationship between lakes and inland rivers (Zhang, 2007). Driven by rainfall and evaporation, the model involves two simulation processes: surface runoff and 
underground runoff. It takes into consideration major hydraulic process, such as canopy interception, catchment evapotranspiration, soil water storage, slope runoff, groundwater recharge and runoff, and river runoff. Surface runoff is simulated by spatial discrete raster (Zhang, 2009). Each raster has different hydrogeological parameters and input data by remote sensing interpretation. In view of different characteristics of saturated soil and unsaturated soil, for underground runoff, finite difference is used to disperse saturated zone and analytic equation is used to simulate unsaturated soil (Liu and Zhang, 2009).

Input data like Digital Elevation Model (DEM), land use, evapotranspiration, soil characteristics, daily rainfall, and a large quantity of information including soil moisture, soil and underground water recharge, and lake runoff can be outputted. The main structure of the model is shown in Figure 1.

Researches on Poyang Lake based on WATLAC model have been recognized all over the world. For example, Fan et al. (2005) verify the model based on measured data between 1960 and 1989 of Waizhou Station and Xiajiang Station. During the calibration period, the annual runoff of the two stations has an error less than $8 \%$. This shows that the model has better simulation. Ye et al. (2011) combine ECHAM5 and WATLAC to predict the runoff of Poyang Lake in the context of future climate. Compared with the measured data of six hydraulic stations, the predicted result has a certainty factor above 0.7, indicating a better simulation of the model. Li et al. (2014) use measured data of lake runoff, lake level, outlet volume and etc. to verify the model. The certainty factor is above 0.75 , showing a better simulation of the model. These researches show that distributed hydrological model WATLAC has been successfully applied in the research of Poyang Lake. The paper therefore, adopts the model to establish runoff series of Poyang Lake in the past millennium.

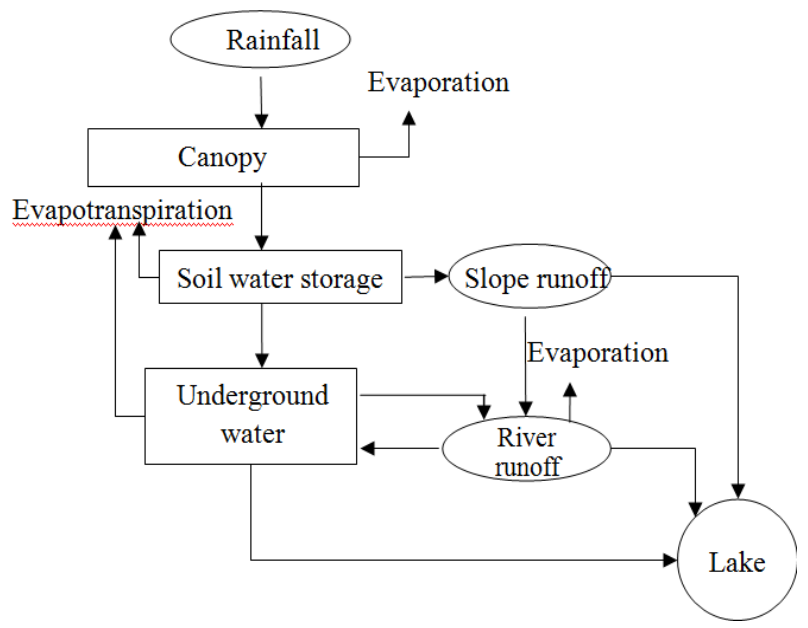

Figure 1. The simulated hydrology process of Model WATLAC

\section{Result Analysis}

\section{Features of Rainfall-Runoff Changes}

This paper focuses on the features of interannual-interdecadal changes based on an understanding of rainfall-runoff series in the past millennium obtained from the mean value of rainfall-runoff at different time scale of 1 year, 5-year, 10-year, 20-year, 30- 
year. Simulation results of rainfall series based on CCSM4 and ECHAM5 are shown in Figure 2. Figure 2 respectively shows simulating changes of 10-year average anomaly for depth of rainfall runoff of Poyang Lake in the past millennium based on CCSM4 and ECHAM5. CCSM4 model includes the runoff series between 1040 and 1850, 810 years in all. ECHAM5 model includes the runoff series between 1000 and 1959, 960 years in all. The two models differ a little in the simulation of dry-wet changes during the MWP and LIA periods.

For the MWP period, CCSM4 model shows that runoff ranges around the mean value and that dry and wet situation appear alternatively. In terms of the rainfall, $45 \%$ of the years have a dry weather, and $38 \%$ have runoff. The distribution is relatively even. For the LIA period, dry-wet situation changes drastically and easily causes extreme drought or flood. $53 \%$ of the years have rainfall and $41 \%$ have runoff. Both appear in the dry years. The wet years appear alternatively with dry years. The dry-wet situation changes significantly. On the whole, according to CCSM4 model, dry and wet situation appear alternatively and the changes of rainfall and runoff are similar. For the MWP period, ECHAM5 shows that 56\% of the years have a low rainfall and $49 \%$ have a low runoff. For the LIA period, 59\% of the years have a low rainfall and 55\% have a low runoff. According to this model, dry-wet situation remains for a long time.

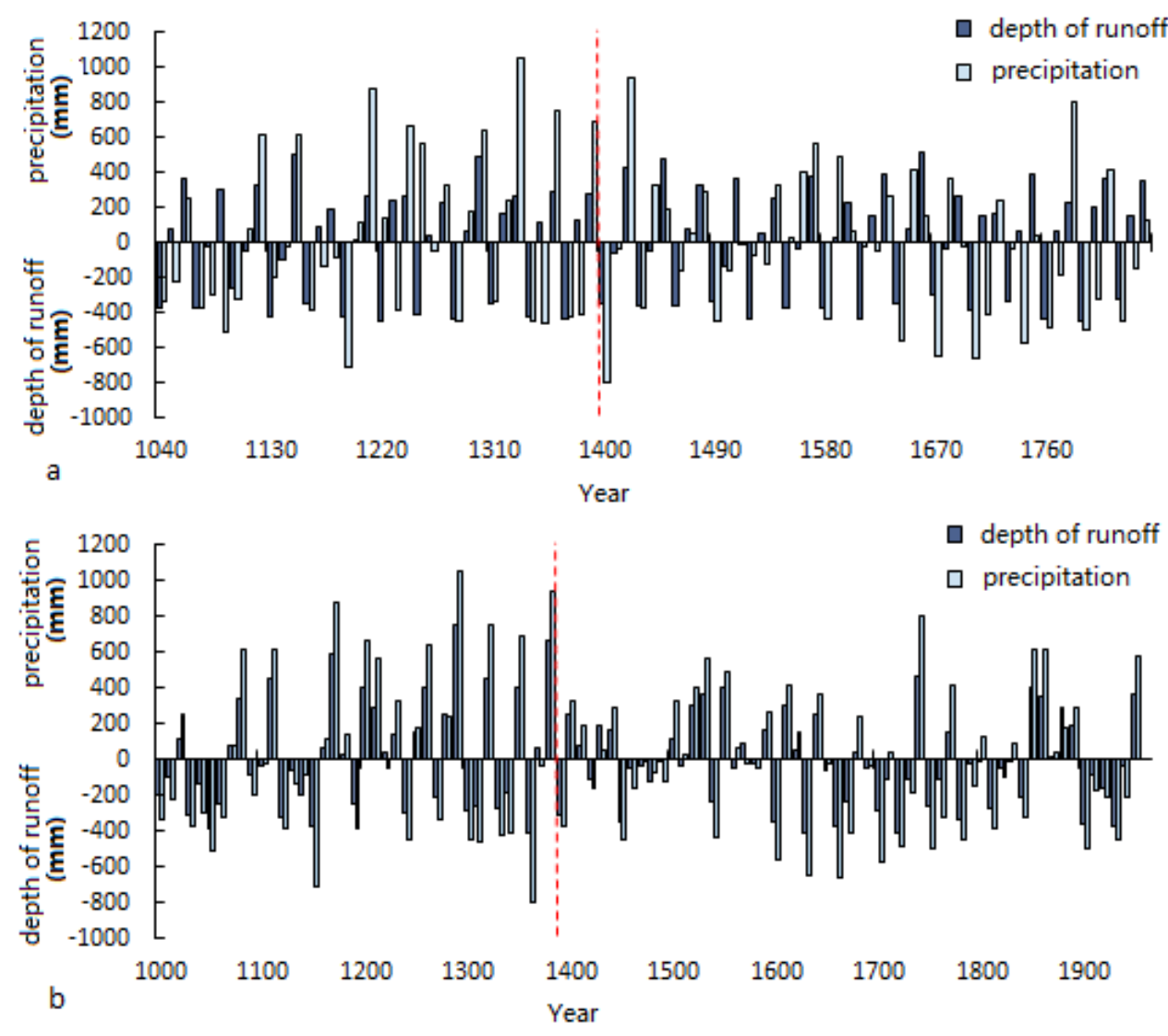

Figure 2. Variances of anomaly of precipitation and runoff on 30-year time scale. Picture (a) represents the model CCSM4 and (b) is ECHAM5. The red dash line divided the picture into period MWP and period LIA 


\section{Periodic Changes of Rainfall-Runoff}

The periodical changes of rainfall-runoff depth series based on CCSM4 and ECHAM5 are shown in Figure 3. Fast Fourier Transform (FFT) results can easily identify strong and weak changes of time series on different scales. Figure $a$ and $b$ in Figure 3 show that both models have several peak values, indicating the strongest vibration at certain frequency. Corresponding frequency of rainfall-runoff depth series at the peak value has a higher matching level. This indicates that rainfall and depth of runoff have the same vibration period on the time scale. In CCSM4 model frequency above confidence curve involves $0.033,0.101$ and 0.133 . In ECHAM5 model frequency above confidence curve involves $0.034,0.066$ and 0.133 . The recurrence intervals of rainfall-runoff series in the two models are similar, suggesting the synchronous changes of runoff process and rainfall process. In view of the statistical meaning of the period, here listed are the first three periods.
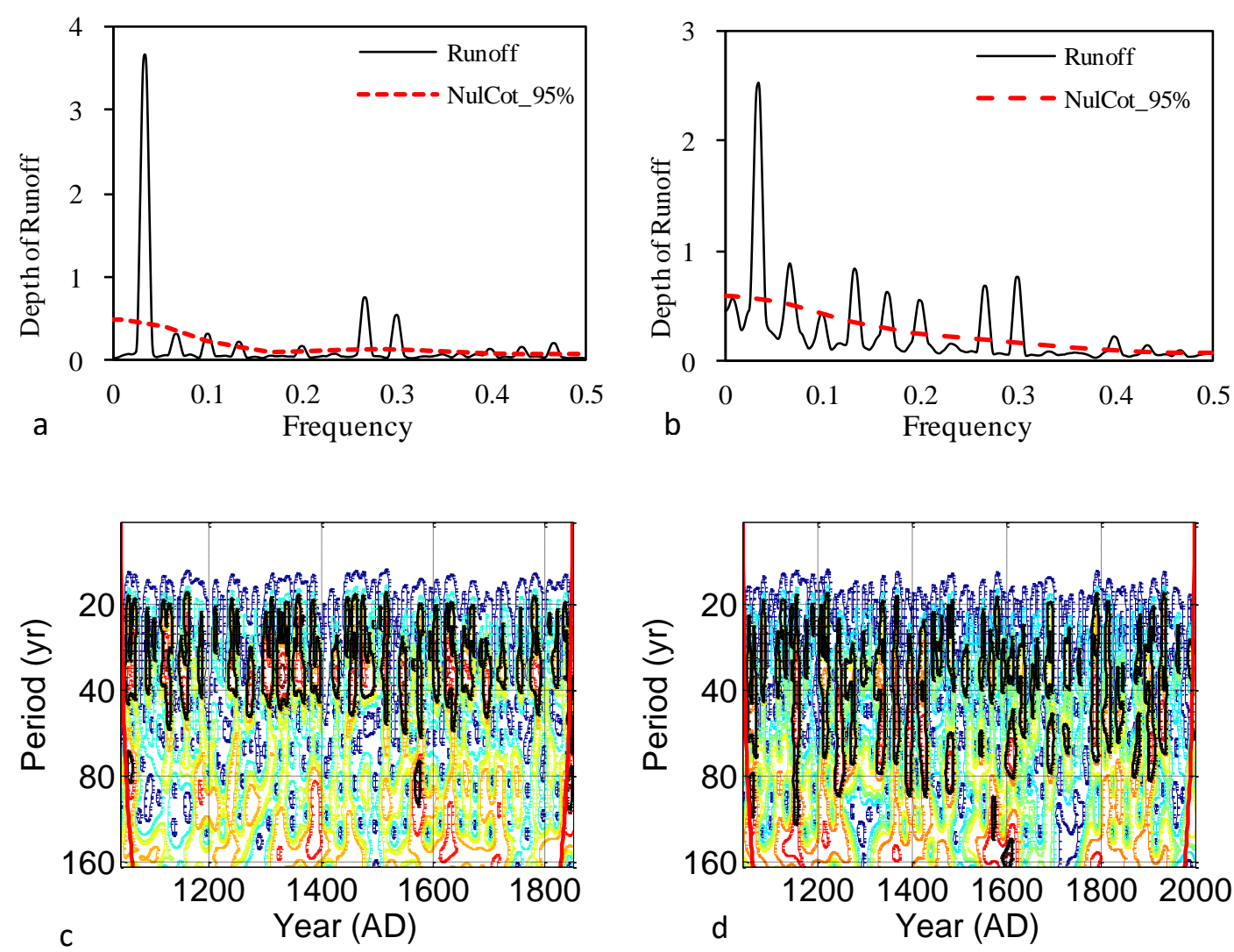

Figure 3. $(a$ and $b$ ) Fast Fourier transform spectral power spectrum of depth of runoff. The black full line and dash line indicate spectral power of precipitation and depth of runoff respectively. And the red ones mean their own 95\% confidence line. ( $c$ and d) Wavelet power spectrum contours of depth of runoff for CCSM4 model and ECHAM5. It was plotted by time series against periods, in which the $95 \%$ confidence contour was in black part and the red full line meant cone of influence. Any part below the red line is not reliable.

Period distribution in Wavelet Transform module square time frequency distribution contour is similar to that in FFT. Figure $3 c$ shows that in CCSM4 model both rainfall and depth of runoff are strongest on time scale of 20 to 40-year, with the energy center 
around 30-year. According to Figure 3, in ECHAM5 model confidence region is at 20 to 80-year, but the energy center with continuous changes is basically around 30-year. Power spectrum contours of rainfall and runoff series in both models are basically the same. This further shows that though flow process is influenced by some factors, it mainly changes with rainfall process on time scale. According to the analysis results of the models, the period of rainfall-runoff change of Poyang Lake in the past millennium is around 30-year.

\section{Hydrological and Meteorological Series and Frequency and Period of Extreme Events}

Figure $4 a$ and $4 b$ are FFT power spectrums of rainfall based on CCSM4 and ECHAM5 respectively. For the sake of comparison, Figure $4 c$ and $4 d$ show FFT power spectrum of rainfall-runoff respectively based on the two models.
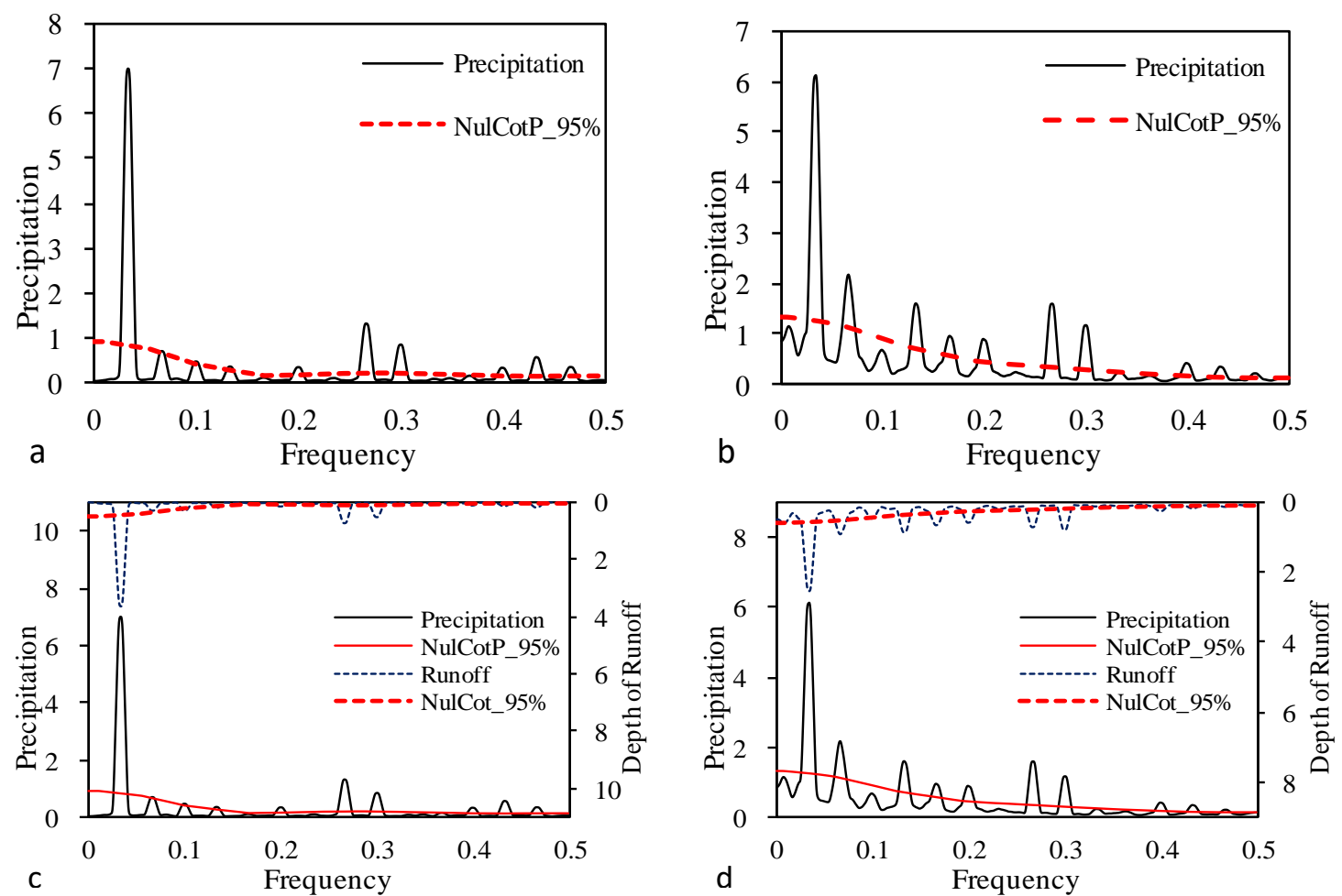

Figure 4. ( $a$ and $b$ ) Fast Fourier transform spectral power spectrum of precipitation and depth of runoff. ( $c$ and d) Spectral power spectrum between precipitation and depth of runoff. The

black full line and dash line indicate spectral power of precipitation and depth of runoff respectively. And the red ones mean their own $95 \%$ confidence line

According to Figure 4, power spectrum change distribution of rainfall series and runoff series are basically the same. The peak value of rainfall series is bigger, indicating a high frequency of extreme rainfall events. Similar power spectra reflect the corresponding relationship between the extreme runoff and the climate.

Figure $5 a$ is Wavelet Transform module square time frequency distribution of rainfall anomaly based on CCSM4 model. Figure $5 b$ is Wavelet Transform module square time frequency distribution of rainfall anomaly based on ECHAM5 model. 

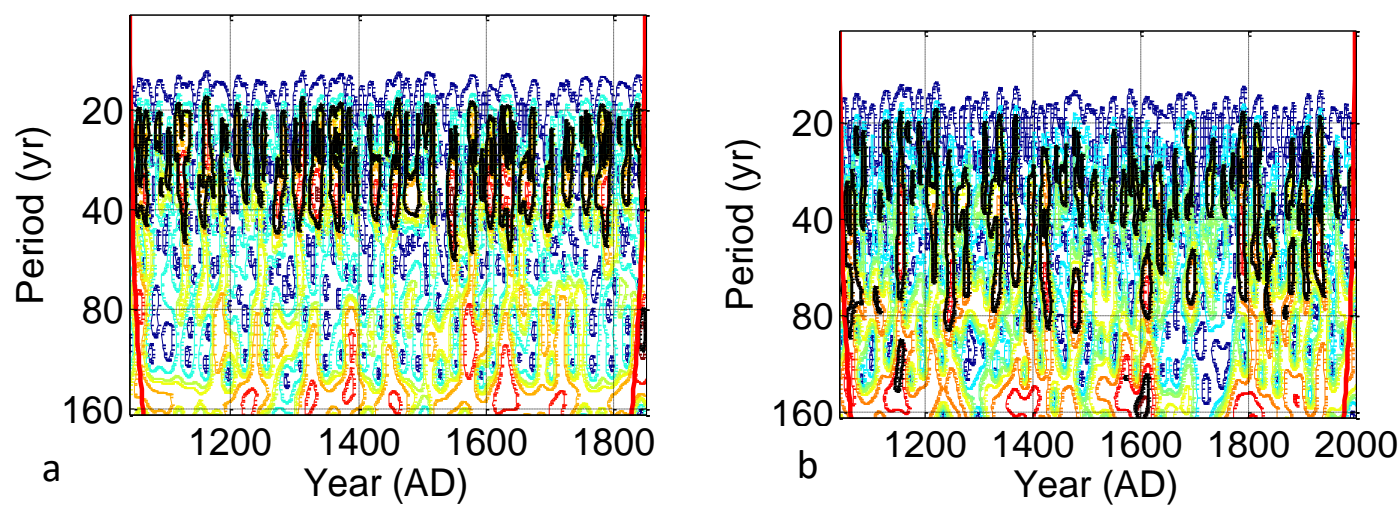

Figure 5. $(a$ and $b$ ) Wavelet Transform module square time frequency distribution of depth of precipitation for CCSM4 model and ECHAM5 model. It was plotted by time series against periods, in which the $95 \%$ confidence contour was in black part and the red full line meant cone of influence. Any part below the red line is not reliable

Rainfall period shown in Figure 5 is similar to that in FFT, and to module square distribution of runoff depth in Figure 3. In CCSM4 model rainfall has the strongest energy between 20-40 year, with the energy center at around 30-year. .ECHAM5 model has confidence region between 20 and 80-year, but the energy center with continuous changes basically remains at 30-year. According to the figure, both models show that in the past millennium Poyang Lake had similar rainfall process and runoff process, with 30 -year being the period. This again displays the corresponding relationship between the runoff and the climate.

\section{Conclusion}

This paper simulates the runoff series of Poyang Lake in the past millennium and explains the hydrological changes, features and dynamic mechanism of this area under the influences of climate changes. Nowadays extreme hydrological events happening in Poyang Lake area are mainly caused by rainfall and surface confluence. And a regression analysis of historical situation can offer reliable scientific proof for predicting future extreme hydrological events. The runoff period of Poyang Lake in the past millennium is 30 years, similar to the current runoff research results of Poyang Lake. This further proves the influence of climate changes on hydrological process in the area on the time scale.

- Rainfall and runoff of Poyang Lake in the past millennium have a similar variation trend based on CCSM4 and ECHAM5 models through down-scaling methods. This shows the basic characteristics of atmosphere circulation under the influence of radiation and the formation of basic rainfall pattern. Runoff changes a little differently based on the two models. In ECHAM5 model there is a longer time of dry years, while in CCSM4 model dry years and wet years appear alternatively. In both models, dry years in LIA period is more than those in MWP period.

- According to the FFT analysis of runoff series based on CCSM4 and ECHAM5 models, the runoff series shows main period 30 years and 29 years with peak value, secondary period between 10 and 15 years, and the $3^{\text {rd }}$ period around 7 years. The analysis shows that the main period is related to atmospheric 
oscillation and Pacific decadal oscillation; the secondary period is related to solar activity; and the $3^{\text {rd }}$ period is related to El Nino influenced by radiation and atmospheric action. Changes of atmospheric oscillation reflect the macro features of a regional climate. In terms of changes on interdecadal and interannual scale, what matters is interior vibration of climate system and air-sea-land interaction. According to the wavelet analysis, relatively strong signals appear between 20 and 40 years in CCSM4 model and between 20 and 80 years in ECHAM5 model, but the peak value of energy appears around 30 years. The results are similar to FFT results. Within the same model, module square distribution of rainfall-runoff series has a similar energy distribution. This indicates that rainfall and runoff have the same vibration changes on the millennium scale. This phenomenon reveals the atmospheric oscillation in the millennium, which is helpful in understanding features and rules of regional climate changes against the natural climate changes.

Acknowledgements. This research was supported by the Jiangsu Province Natural Science Foundation (BK20130842), the Project supported by the National Natural Science Foundation of China (51409091), and the Fundamental Research Funds for the Central Universities (2015B14614).

\section{REFERENCES}

[1] Blackmon, M., Boville, B., Bryan, F. (2001): The community system model. - Bull. Amer. Meteor. Soc 82(11): 2357-2376.

[2] Bueh, C., Lin, Y.H. (2003): A Simulation of the Annual Cycle and Future Change of the East Asian Monsoon with the ECHAM4/OPYC3 CGCM Model. - Climatic and Environmental Research 8(4): 402-416.

[3] Fan, L. J., Fu, C. B.,Chen, D. L. (2005): Review on Creating Future Climate Change Scenarios by Statistical Downscaling Techniques. - Advance in Earth Science 20(3): 320-329.

[4] Guo, H., Jiang, T., Wang, G. J., Su, B. D. (2006): Wang Yanjun. Observed trends and jumps of climate change over Lake Poyang Basin, China: 1961-2003. - Journal of Lake Sciences 18(5): 443-451.

[5] Jiang, H., Zhou, G. W., Liu, C. L. (2007): Study on dynamics of vegetation coverage by remote sensing in Poyang Lake Area. - Acta Agriculture Jiangxi 19(1): 103-106.

[6] Jiang, L. G., Feng, Z. M., Yu, X. B., et al. (2010): Scenario Analysis on the Flood Regulation Service of the Poyang Lake Region. - Resources Science 32(5): 817-823.

[7] Li, Y. L., Qi, Zhang., et al. (2014): Hydrodynamic and Hydrological Modeling of the Poyang Lake Catchment System in China. - Journal of Hrdrologic Engineering 19: 607616.

[8] Liu, J., Zhang, Q. (2009): Verification of a New Distributed Hydrologic Model in Ganjing River Catchment, Poyang Lake Watershed. - Resources and Environment in the Yangtze Basin 18(1): 19-26.

[9] Liu, K. (2011): Comparison and analysis for the result of multi-model ensembles of GCM and result of RCM in China [Dissertation ] . - Beijing: Chinese Academy of Agricultural Science.

[10] Liu, X. D., Ren, B. F. (2014): Analysis on variation characteristics and genesis of lower water level of Poyang Lake. - Yangtze River 45(4): 12-16.

[11] Qin, D. H., Thomas, S. et al. (2014): Highlights of the IPCC working group fifth assessment report. - Progressus Inquisitiones de Mutatione Climatis 10(1): 1-6. 
[12] Tian, Z.,Jiang, D. B. (2013): Evaluation of the performance of low- to high-resolution CCSM4 over East Asia and China. - Chinese Journal of Atmospheric Sciences 37 (1): 171-186. (in Chinese)

[13] Tian, Z. P.,Jiang, D. B., Zhang, R., Sui, Y. (2012): Long-term climate simulation of CCSM4.O and evaluation of its performance over East Asia and China. - Chinese Journal of Atmospheric Sciences(in Chinese) 36(3): 619-632.

[14] Xu, J. J., Chen, J. (2009): Discussion on schemes of ecological water conservancy project for the Poyang Lake mouth. - Yangtze River 40(3): 17-19,24.

[15] Ye, X. C., Zhang, Q., Bai, L. (2011): A modeling study of catchment discharge to Poyang Lake under future climate in China. - Quaternary International 244: 221-229.

[16] Yu, D. J., Hu, Z. P. (2010): Research on the development of eco-industry in Poyang Lake eco-economic zone. - Resources and Environment in the Yangtze Basin 19(3): 231-236.

[17] Yu, G., Harrison, S. (1996): An evaluation of the simulated water balance of Eurasia and northern Africa at 6000 yr B.P. using lake status data. - Climate Dynamics 12: 723-735.

[18] Yu, G., Liao, M. N., Li, Y. F. (2013): Responses of lake ecosystem to the climate changes of the past 1000 years - Case study of dynamic simulations for ecosystem changes of Poyang Lake. - Quaternary Sciences 33(6): 1148-1159. ( in Chinese).

[19] Yu, G., Shen, H., Liu, J. (2009): Impacts of climate change on historical locust outbreaks in China. - Journal of Geophysical Research - Atmospheres 114: 18-104.

[20] Zhang, Q. (2007): Coupled Simulation of Surface and Subsurface Runoffs for Lake Catchments. - Progress in Geography 26(5): 1-10.

[21] Zhang, Q. (2009): Werner Adrian D.Integrated surface-subsurface modeling of Fuxianhu Lake catchment, southwest China. - Water Resource Manage 23: 2189-2204.

[22] Zhai, J. Q., Zeng, X. F., Su, B. D., Xiang, T. (2009): Patterns of Dryness/Wetness in China Before 2050 Projected by the ECHAM5 Model. - Aavances in Climate Change Research 5(4): 220-225.

[23] Zhu, H. H., Zhang, B. (1997): Poyang Lake. - Press of University of Science and Technology of China. 